\title{
Implementasi fuzzy inference system untuk pengambilan keputusan
}

\author{
(Implementation of fuzzy inference system for decision making)
}

\author{
Upic Resta Fauziah Tolang ${ }^{1}$, Sugiyarto ${ }^{2^{*}}$ \\ ${ }^{12}$ Department of Mathematics, Ahmad Dahlan University, Yogyakarta, Indonesia. \\ E-mail: sugiyartonf@yahoo.com \\ * Corresponding Author
}

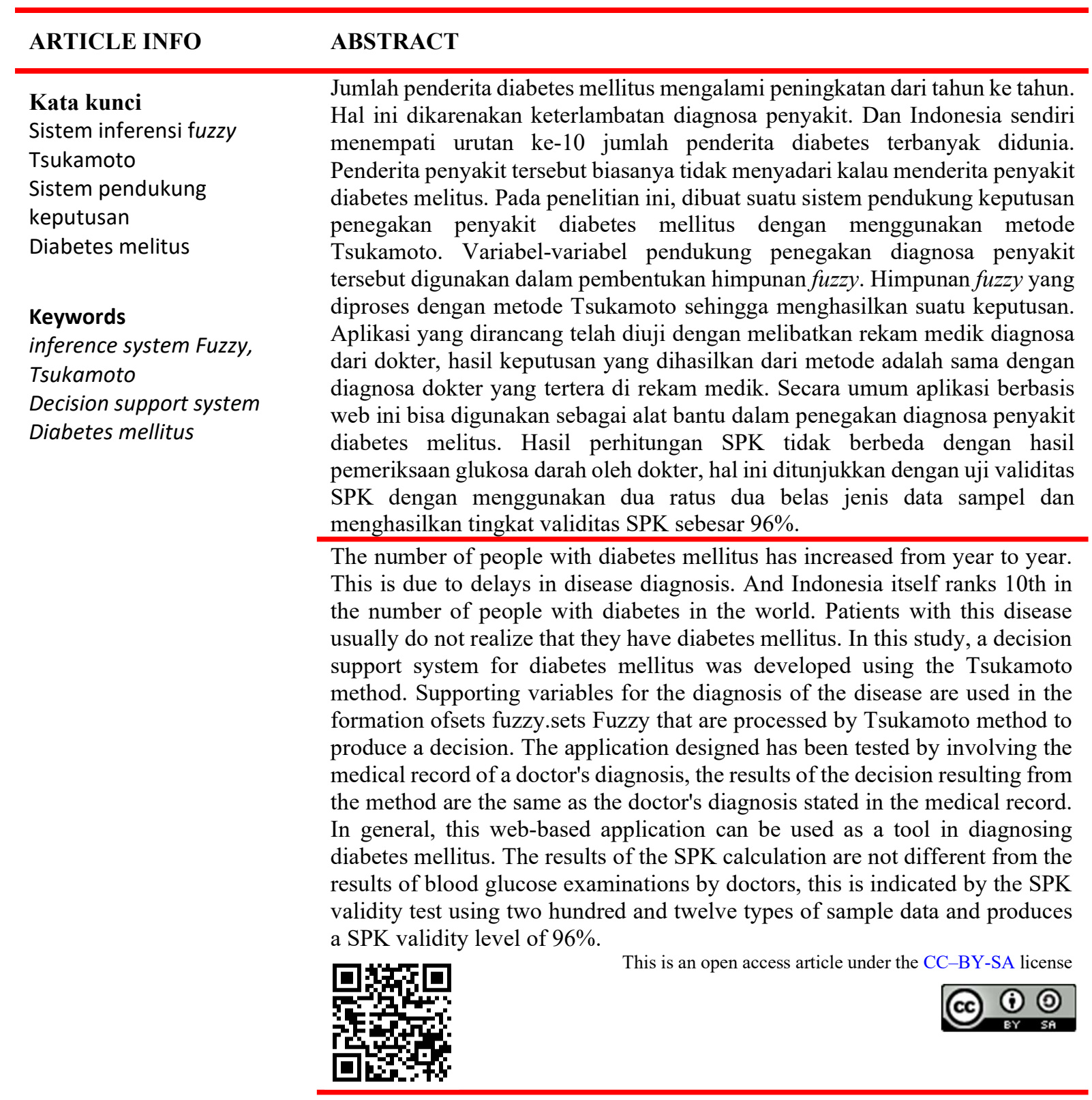




\section{PENDAHULUAN}

Pada tahun 1965, Profesor Lotfi Asker Zadeh, seorang guru besar University of California mempublikasikan karya ilmiah berjudul "Fuzzy sets". Lotfi A. Zadeh mengemukakan teori fungsi keanggotaan yang dioperasikan dengan bilangan real diantara nilai benar 1 dan salah 0 . Ia pula yang mempopulerkan aturan maksimum dan minimum yang diperoleh dari operasi himpunan fuzzy [1][2][3].

Sistem fuzzy memiliki keunggulan dalam memodelkan aspek kualitatif dari pengetahuan manusia dan proses pengambilan keputusan (reasoning) sebagaimana dilakukan oleh manusia dengan menerapkan basis aturan. Sistem fuzzy dapat mengatasi kesulitan dalam melukiskan suatu sistem fisis yang komplek dan sukar dimodelkan secara matematis. Berdasarkan keunggulan yang terdapat pada sistem fuzzy, maka sistem tersebut dapat digunakan sebagai dasar terbentuknya suatu sistem pendukung keputusan.

Sistem Pendukung Keputusan (SPK) adalah suatu sistem informasi berbasis komputer yang menghasilkan berbagai alternatif keputusan untuk membantu manajemen dalam menangani berbagai permasalahan yang terstruktur ataupun tidak terstruktur dengan menggunakan data dan model. Tujuan dari penerapan sistem pendukung keputusan adalah untuk mendukung pengambil keputusan memilih alternatif hasil pengolahan informasi dengan model pengambil keputusan serta untuk menyelesaikan masalah yang bersifat semiterstruktur dan tidak terstruktur[4][5]. Berdasarkan ketujuh model tersebut salah satu model yang cukup populer dalam penyelesaian masalah adalah model heuristik dan Fuzzy Inference System (FIS) merupakan salah satu bagian dari model ini [6].

Sistem Inferensi Fuzzy (Fuzzy Inference System atau FIS ) disebut juga fuzzy inference engine adalah sistem yang dapat melakukan penalaran dengan prinsip serupa seperti manusia melakukan penalaran dengan nalurinya. Sistem inferensi fuzzy juga merupakan kerangka komputasi yang didasarkan pada teori himpunan fuzzy, aturan fuzzy berbentuk $I F-T H E N$, dan penalaran fuzzy. Ada tiga metode dalam sistem inferensi fuzzy, yaitu: Metode Tsukamoto, Metode Mamdani, dan Metode Sugeno [7][8]. Metode Tsukamoto dipilih karena setiap konsekuen pada aturan yang berbentuk IF-THEN direpresentasikan dengan himpunan fuzzy dengan fungsi keanggotaan yang monoton. Sebagai hasilnya, output dari setiap aturan diberikan secara tegas berdasarkan $\alpha$-predikat, kemudian diperoleh hasil akhir dengan menggunakan rata-rata terpusat.

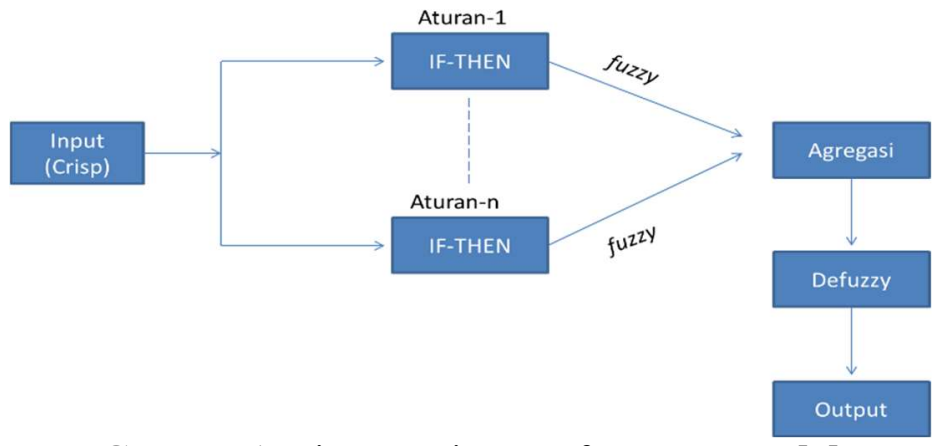

Gambar 1. Diagram Sistem Inference Fuzzy [5]

Salah satu penerapan fuzzy inference system adalah dalam bidang kedokteran, yakni implementasi fuzzy inference system dalam mendiagnosa penyakit diabetes melitus[9][10][11]. Diabetes melitus atau kencing manis merupakan penyakit kronis yang ditandai dengan kelainan metabolik akibat dari kurangnya produksi insulin oleh pankreas. Diabetes melitus telah dikategorikn sebagai salah satu penyakit tidak menular yang banyak merenggut nyawa penderitanya dan diketahui telah menjadi persoalan kesehatan serius didunia. Peran pencegahan untuk menanggulangi jumlah penderita diabetes di Indonesia disebabkan salah satunya jumlah endokrinologi di Indonesia yang masih terbilang sedikit. Hal ini disebabkan karena keterlambatan diagnosis sejak dini oleh penderita diabetes melitus. 


\section{METODE}

\subsection{Populasi penelitian}

Populasi dalam penelitian adalah pasien Puskesmas Lendah Kulon Progo. Pada penelitian ini sampel yang digunakan adalah data pasien yang berkunjung ke poli penyakit dalam Puskesmas Lendah Kulon Progo. Data pasien diabetes melitus dapat dilihat pada Tabel.1.

Table 1. Data Pasien Diabetes Melitus Puskesmas Lendah Kulon Progo

\begin{tabular}{|c|c|c|c|c|c|}
\hline No & $\begin{array}{c}\text { GDP } \\
(\mathrm{mg} / \mathrm{dl})\end{array}$ & $\begin{array}{c}\text { GD } \\
(\mathrm{mg} / \mathrm{dl})\end{array}$ & $\begin{array}{c}\text { GDPS } \\
(\mathrm{mg} / \mathrm{dl})\end{array}$ & $\begin{array}{l}\text { HbA1c } \\
(\mathrm{mg} / \mathrm{dl})\end{array}$ & $\begin{array}{c}\text { Diagnosa } \\
\text { Dokter }\end{array}$ \\
\hline 1 & 113 & 126 & 178 & 3 & Pra DM \\
\hline 2 & 146 & 90 & 113 & 3.3 & Pra DM \\
\hline 3 & 209 & 166 & 102 & 6 & Pra DM \\
\hline 4 & 146 & 93 & 180 & 2.5 & Pra DM \\
\hline 5 & 131 & 82 & 197 & 3 & Pra DM \\
\hline 6 & 155 & 109 & 156 & 2 & Pra DM \\
\hline 7 & 143 & 79 & 187 & 8 & DM \\
\hline 8 & 320 & 83 & 168 & 4.1 & Pra DM \\
\hline 9 & 156 & 138 & 146 & 6 & Pra DM \\
\hline 10 & 143 & 140 & 169 & 6.3 & Pra DM \\
\hline \multicolumn{6}{|l|}{. } \\
\hline \multicolumn{6}{|l|}{. } \\
\hline 212 & 182 & 209 & 542 & 6.5 & $\mathrm{DM}$ \\
\hline
\end{tabular}

\subsection{Logika Fuzzy}

Definisi.1.1 Menurut [12] suatu himpunan fuzzy Ã dalam X didefinisikan sebagai himpunan pasangan berurut:

$$
\tilde{A}=\{x, \mu \tilde{A}(x)) \mid x \in X\}
$$

dengan $\mu_{\tilde{A}}(x)$ adalah derajat keanggotaan $\mathrm{x}$ dalam $\tilde{\mathrm{A}}$ yang memetakan $\mathrm{x}$ ke ruang keanggotaan $\mathrm{X}$ yang terletak pada rentang $[0,1]$.

\subsection{Sistem Pendukung Keputusan}

Sistem Pendukung Keputusan (SPK) adalah sistem informasi berbasis komputer yang menyediakan dukungan informasi yang interaktif bagi manajer dan praktisi bisnis selama proses pengambilan keputusan [13]. Menurut [14] SPK dibangun oleh tiga komponen: Model base, Database, dan Software system. Validasi SPK digunakan untuk mengetahui SPK valid atau tidak. Untuk menguji tingkat validitas SPK dapat dilihat dalam Tabel. 2.

Tabel 2. Hasil uji validasi SPK

\begin{tabular}{cccc}
\hline $\begin{array}{c}\text { Data } \\
\text { ke- }\end{array}$ & SPK & $\begin{array}{c}\text { Diagnosa } \\
\text { Dokter }\end{array}$ & $\begin{array}{c}\text { Ket } \\
\text { (T/F) }\end{array}$ \\
\hline 1 & Hasil & Hasil & $\mathrm{T}$ \\
& SPK-1 & diagnosa-1 & \\
2 & Hasil & Hasil & $\mathrm{F}$ \\
& SPK-2 & diagnosa-2 & \\
3 & Hasil & Hasil & $\mathrm{T}$ \\
& SPK-3 & diagnosa-3 & \\
4 & Hasil & Hasil & $\mathrm{F}$ \\
& SPK-4 & diagnosa-4 & \\
. & $\cdot$ & $\cdot$ & $\cdot$ \\
$\cdot$ & $\cdot$ & $\cdot$ & $\cdot$ \\
$\cdot$ & $\cdot$ & $\cdot$ & $\cdot$ \\
$\mathrm{n}$ & Hasil & Hasil & $\mathrm{T}$ \\
& SPK-n & diagnosa-n & \\
\hline
\end{tabular}


Keterangan:

$\mathrm{T}=$ True. Terjadi apabila hasil perhitungan SPK sama dengan hasil diagnosa dokter.

$\mathrm{F}=$ False. Terjadi apabila hasil perhitungan SPK tidak sama dengan hasil diagnosa dokter.

Menurut Teddy Rismawan (2008) tingkat validitas SPK dapat dicari dengan persamaan:

$$
\text { Tingkat validitas } S P K=\frac{\text { banyaknya hasil pengujian bernilai } T}{\text { banyaknya data sampel }} \times 100 \%
$$

\section{Implementasi Sistem Pendukung Keputusan (SPK)}

Komponen SPK yang digunakan dalam mengembangkan SPK ini yaitu: Model base, Database, dan Software System.

1. Model Base Metode Tsukamoto

a) Menentukan Himpunan Fuzzy

Tabel 3. Himpunan Fuzzy [14]

\begin{tabular}{ccccc}
\hline No & Variabel Fuzzy & Rendah & $\begin{array}{c}\text { Himpunan Fuzzy } \\
\text { Sedang }\end{array}$ & Tinggi \\
\hline 1 & $\begin{array}{c}\text { Gula Darah Puasa } \\
(\mathrm{mg} / \mathrm{dl})\end{array}$ & $<86$ & $86 \leq \mathrm{GDP} \leq 126$ & $>126$ \\
2 & $\begin{array}{c}\text { Gula Darah } 2 \text { Jam } \\
\text { PP (mg/dl) }\end{array}$ & $<100$ & $100 \leq \mathrm{GD} \leq 140$ & $>140$ \\
3 & $\begin{array}{c}\text { Gula Darah Plasma } \\
\text { Sewaktu (mg/dl) } \\
\text { Kadar HbA1c } \\
(\text { mg/ml) }\end{array}$ & $<160$ & $160 \leq \mathrm{GDPS} \leq 200$ & $>200$ \\
5 & $<4,5$ & $4,5 \leq \mathrm{HbA} 1 \mathrm{c} \leq 6,5$ & $>6,5$ \\
5 & $\begin{array}{c}\text { Keputusan Diagnosa } \\
(\mathrm{mg} / \mathrm{dl})\end{array}$ & $<3,5$ & $3,5 \leq$ Diagnosa $\leq 6,5$ & $>6,5$ \\
\hline
\end{tabular}

b) Mendefinisikan Variabel Fuzzy

I. Variabel Gula Darah Puasa $(\mathrm{mg} / \mathrm{dl})$

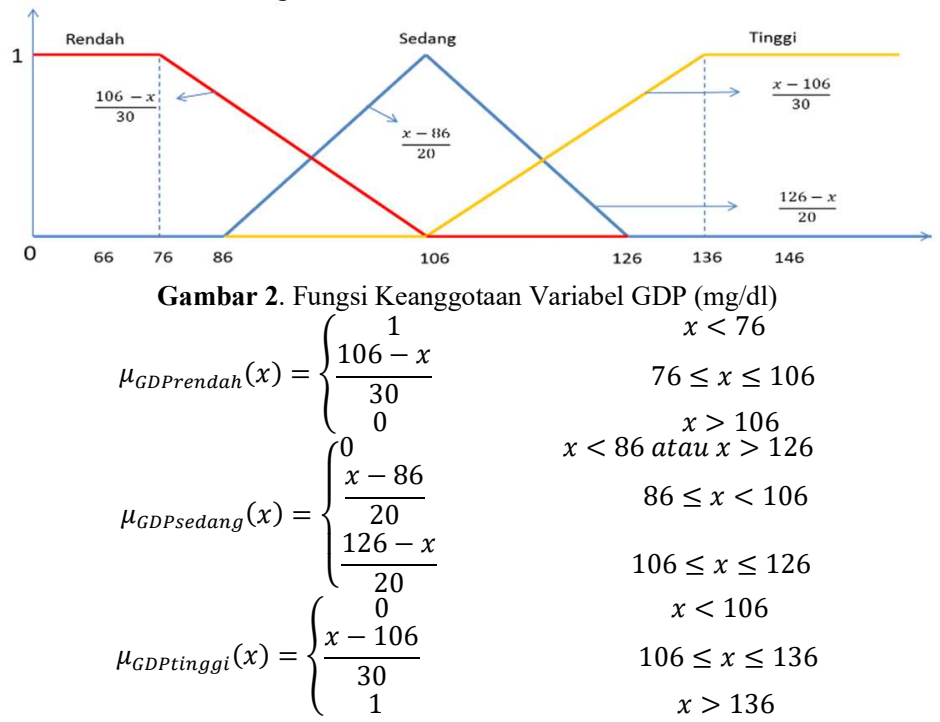

II. Variabel Gula Darah 2 Jam PP (mg/dl)

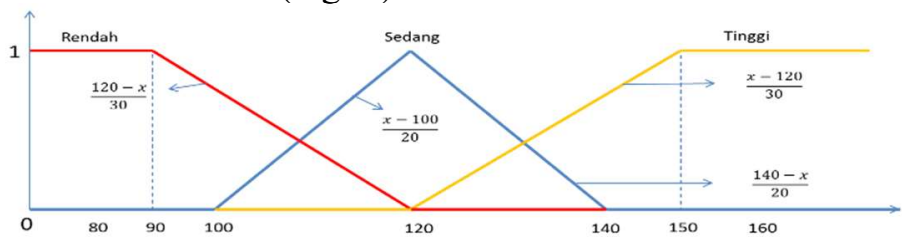


Jurnal Ilmiah Matematika, 7 (1), 2020 - 47

Upic Resta Fauziah Tolang, Sugiyarto

$$
\begin{array}{r}
\text { Gambar 3. Fungsi Keanggotaan Variabel GD }(\mathrm{mg} / \mathrm{dl}) \\
1 \\
\mu_{\text {GDrendah }}(x)=\left\{\begin{array}{cc}
\frac{120-x}{30} & 0 \leq x \leq 120 \\
0 & x>120
\end{array}\right. \\
\mu_{\text {GDsedang }}(x)=\left\{\begin{array}{lc}
0 & \frac{x-100}{20} \\
\frac{140-x}{20} & 100 \leq x<120
\end{array}\right. \\
\mu_{\text {GDtinggi }}(x)=\left\{\begin{array}{cc}
\frac{x-120}{30} & x<120 \\
\frac{x}{1} & 120 \leq x \leq 150
\end{array}\right.
\end{array}
$$

III. Variabel Gula Darah Plasma Sewaktu (mg/dl)

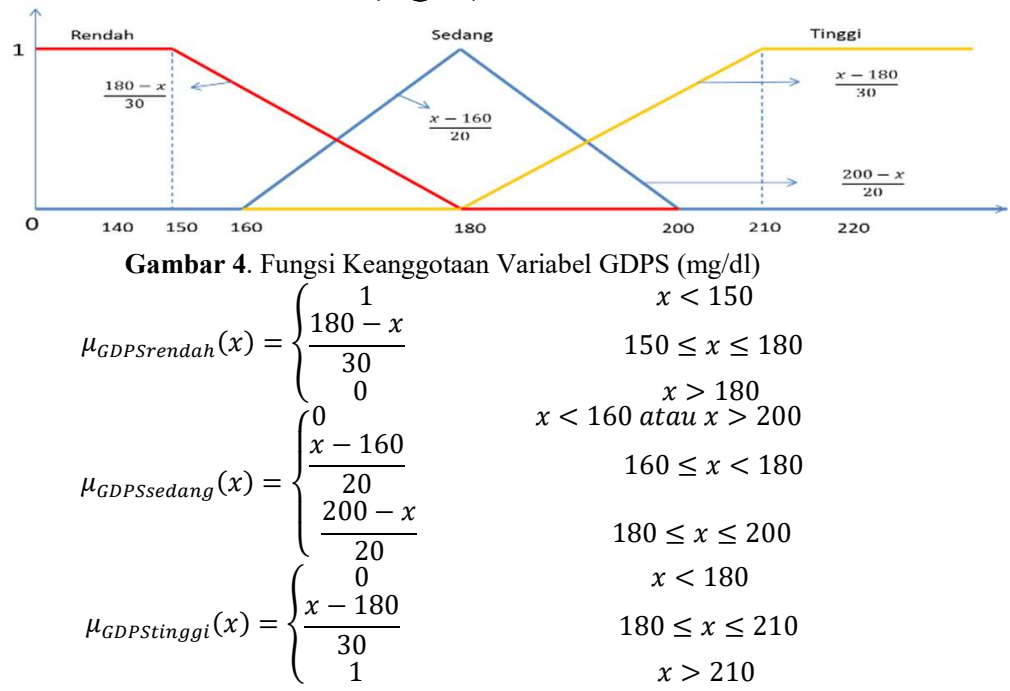

IV. Variabel Kadar HbAlc (mg/dl)

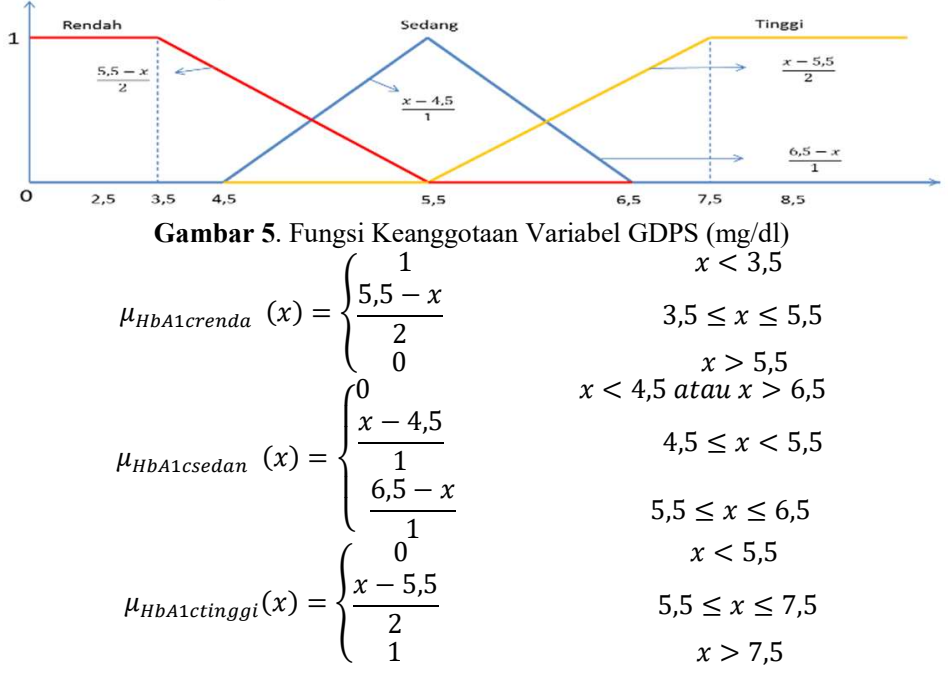

V. Vareiabel Keputusan Diagnosa




Jurnal Ilmiah Matematika, 7 (1), 2020 - 48

Upic Resta Fauziah Tolang, Sugiyarto

$$
\begin{array}{r}
\mu_{\text {Normal }}(z)=\left\{\begin{array}{cc}
1 & z<3 \\
\frac{4-z}{1} & 3 \leq z \leq 4 \\
0 & z>4
\end{array}\right. \\
\mu_{\text {PraDM }}(z)=\left\{\begin{array}{lc}
0 & z<3,5 \text { atau } z>6,5 \\
\frac{z-3,5}{1,5} & 3,5 \leq z<5 \\
\frac{6,5-z}{1,5} & 5 \leq z \leq 6,5
\end{array}\right. \\
\mu_{D M}(z)=\left\{\begin{array}{lc}
0 & z<6 \\
\frac{z-6}{1} & 6 \leq z \leq 7 \\
1 & z>7
\end{array}\right.
\end{array}
$$

\begin{tabular}{|c|c|c|c|c|c|c|c|}
\hline \multirow{2}{*}{ No } & & \multicolumn{4}{|c|}{ Anteseden } & & \multirow{2}{*}{ Konsekuen } \\
\hline & & GDP & GD & GDPS & HbA1c & & \\
\hline 1 & IF & RENDAH & RENDAH & RENDAH & RENDAH & THEN & NORMAL \\
\hline 2 & IF & RENDAH & RENDAH & RENDAH & SEDANG & THEN & NORMAL \\
\hline 3 & IF & RENDAH & RENDAH & SEDANG & RENDAH & THEN & NORMAL \\
\hline 4 & IF & RENDAH & SEDANG & RENDAH & RENDAH & THEN & NORMAL \\
\hline 5 & IF & SEDANG & RENDAH & RENDAH & RENDAH & THEN & NORMAL \\
\hline 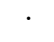 & 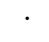 & 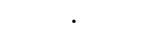 & $\cdot$ & . & . & - & . \\
\hline . & . & . & . & . & . & . & . \\
\hline 81 & IF & SEDANG & TINGGI & $\stackrel{\cdot}{\text { RENDAH }}$ & RENDAH & THEN & $\mathrm{DM}$ \\
\hline
\end{tabular}

c) Inferensi

Inferensi adalah proses penggabungan banyak aturan berdasarkan data yang tersedia [4]. Rumus umum yang digunakan untuk mencari banyaknya aturan fuzzy adalah sebagai berikut:

$\mathrm{n}=$ banyaknya aturan fuzzy

$$
n=a^{b}
$$

$\mathrm{a}=$ banyaknya himpunan fuzzy pada masing-masing variabel fuzzy

$\mathrm{b}=$ banyaknya variabel fuzzy

Tabel 4. Pembentukan aturan fuzzy

Berdasarkan delapan puluh satu aturan tersebut, maka selanjutnya ditentukan nilai $\alpha$ dan $\mathrm{z}$ untuk masing-masing aturan.

Menurut fungsi keanggotaan keputusan diagnosa Normal maka diperoleh rumus:

sehingga diperoleh rumus untuk mencari nilai $\mathrm{z}$.

$$
\frac{4-z}{1}=\alpha
$$

$$
z=4-\alpha(4-3)
$$

Menurut fungsi keanggotaan keputusan diagnosa Pra Diabetes Melitus maka diperoleh rumus:

sehingga diperoleh rumus untuk mencari nilai z.

$$
\frac{z-3,5}{1,5}=\alpha
$$

$$
z=3,5+\alpha(5-3,5)
$$

Menurut fungsi keanggotaan keputusan diagnosa Diabetes Melitus maka diperoleh rumus:

sehingga diperoleh rumus untuk mencari nilai $z$

$$
\frac{z-6}{1}=\alpha
$$

$$
z=6+\alpha(7-6)
$$

d) Menentukan Output Crisp

Pada metode tsukamoto, untuk menentukan output crisp digunakan defuzufukasi rata-rata terpusat, yaitu:

Dengan $\mathrm{i}=1,2,3, \ldots, 81$

$$
Z=\frac{\sum_{i=1}^{n} \alpha_{i} z_{i}}{\sum_{i=1}^{n} \alpha_{i}}
$$


2. Database

Database pada penelitian ini menggunakan kombinasi antara matlab dan excel dengan formal xlsread, sistem database dirancang dengan tampilan menu utama seperti berikut:

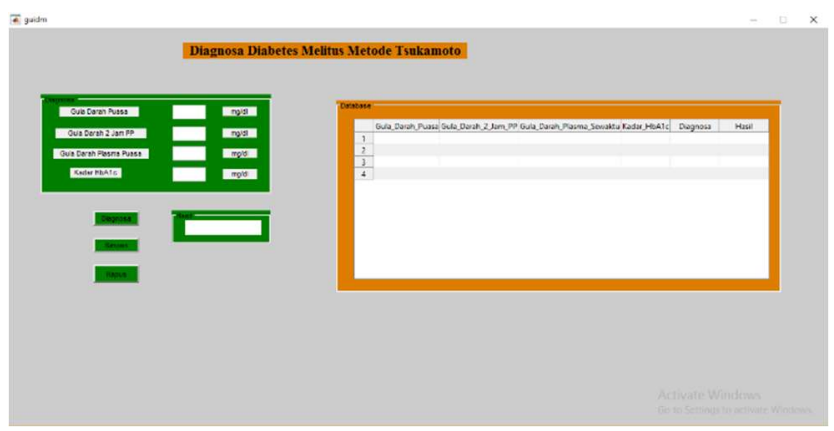

Gambar 7. Tampilan utama Database

\section{Software system}

Dalam mengembangkan SPK dengan metode Tsukamoto ini menggunakan software matlab. Adapun langkah-langkah dalam pengembangan SPK dengan metode Tsukamoto menggunakan software matlab sebagai berikut: mendefinisikan variabel, menentukan fungsi keanggotaan himpunan fuzzy dari tiap variabel, inferensi, dan menentukan nilai output crisp.

\section{SIMPULAN}

Berdasarkan hasil dari perancangan sistem pendukung keputusan dengan pendekatan fuzzy inference system metode Tsukamoto tersebut, maka penulis menarik kesimpulan sebagai berikut:

Penerapan sistem pendukung keputusan dengan pendekatan fuzzy inference system metode Tsukamoto telah terbukti mampu mendiagnosa penyakit diabetes melitus. Karena setelah dilakukan pengujian dengan menggunakan software matlab diketahui hasil dari pengujian tersebut memiliki tingkat validitas sebesar 96\%. Dengan ini sistem pendukung keputusan yang dihasilkan bisa digunakan sebagai alat bantu untuk mendiagnosa penyakit diabetes melitus.

\section{DAFTAR PUSTAKA}

[1] S. Kusumadewi and H. Purnomo, "Aplikasi Logika Fuzzy untuk Pendukung Keputusan, vol. II,” Yogyakarta Graha Ilmu, 2013.

[2] M. A. Setiyaningsih, "Penerapan Metode Tsukamoto dalam Sistem Pendukung Keputusan Penilaian Karyawan pada PT. Pindad (Persero) Berbasis Web.” Universitas Kanjuruhan Malang.

[3] A. I. Falatehan, N. Hidayat, and K. C. Brata, "Sistem pakar diagnosis penyakit hati menggunakan metode fuzzy tsukamoto berbasis android," J. Pengemb. Teknol. Inf. dan Ilmu Komput. e-ISSN, vol. 2548, p. 964X, 2018.

[4] E. Turban, J. E. Aronson, and T. P. Liang, "Decision Support System and Intelligent Systems Edisi 7 Jilid 1," Yogyakarta Andi, 2005.

[5] S. Kusumadewi and S. Hartati, "Neuro-Fuzzy: Integrasi Sistem Fuzzy dan Jaringan Syaraf," Yogyakarta Graha Ilmu, 2006.

[6] F. I. Sanjaya and D. Heksaputra, "Sistem Pendukung Keputusan Pemilihan Tenaga Kontrak Melalui Pendekatan Fuzzy Inference System dengan Metode Tsukamoto (Studi Kasus PT. Solo Murni)," 2016.

[7] S. Setiadji, "Himpunan \& Logika Samar serta aplikasinya," Yogyakarta Graha Ilmu, 2009.

[8] D. A. Puryono, "Metode Fuzzy Inferensi System Mamdani Untuk Menentukan Bantuan Modal Usaha Bagi UMKM Ramah Lingkungan,” 2018.

[9] T. Rismawan, A. W. Irawan, W. Prabowo, and S. Kusumadewi, "Sistem pendukung keputusan 
berbasis pocket pc sebagai penentu status gizi menggunakan metode knn (k-nearest neighbor)," Teknoin, vol. 13, no. 2, 2008.

[10] Y. A. Maulana and B. Nurhadiyono, "Implementasi Fuzzy Tsukamoto dalam Mendiagnosa Penyakit Diabetes Melitus," Progr. Stud. Tek. Informastika, Fak. Ilmu Komputer, Univ. Dian Nuswantoro, 2016.

[11] Z. Niswati, A. Paramita, and F. A. Mustika, "Aplikasi Fuzzy Logic dalam Diagnosa Penyakit Diabetes Mellitus pada PUSKESMAS di Jakarta Timur," J. Nas. Teknol. dan Sist. Inf., vol. 2, no. 3, pp. 21-30, 2016.

[12] C.-T. Lin and C. S. G. Lee, Neural fuzzy systems: a neuro-fuzzy synergism to intelligent systems. Prentice hall, 1996.

[13] J. A. O'Brien, "Pengantar Sistem Informasi: Perspektif Bisnis dan Manajerial Edisi 12," Jakarta: Penerbit Salemba Empat, 2005.

[14] A. Supriyanto, "Pengantar teknologi informasi," Jakarta: Salemba Infotek, 2005. 